\title{
Characterization of Compressive Damage Behavior of Steel and Aluminum
}

\author{
Mohammad R. Allazadeh \\ Institute of Mechanical Engineering, University of Pannonia \\ Veszprem, H-8200, Hungary \\ E-mail: mrallazadeh@yahoo.com
}

Maher K. Itani

Mechanical Engineering Department, University of Pittsburgh

Pittsburgh PA, 15261, USA

E-mail: mki1@pitt.edu

Sylvanus N. Wosu

Mechanical Engineering and Materials Science Department, University of Pittsburgh

Pittsburgh PA, 15261, USA

E-mail: snn2@pitt.edu

Received: October 26, 2011 Accepted: November 2, $2011 \quad$ Published: January 1, 2012

doi:10.5539/jmsr.v1n1p17

URL: http://dx.doi.org/10.5539/jmsr.v1n1p17

\begin{abstract}
Compressive deformation is imposed on aluminum cast 195-76 and ferritic stainless steel 18-8specimens at high strain rateusing perforation split Hopkinson pressure bar (P-SHPB). The energy levels and the compressive dynamic failure behavior of the materials were investigated at high strain rate deformation between 950 and $5700 \mathrm{~s}^{-1}$. This paper investigates the effects of specimen's thickness andimpact energy on failure behavior with correlation of P-SHPB and SHPB.The relationship of different damage mode can be followed with the stress-strain relationship, strain rate and energy absorbed by steel and aluminum specimens.
\end{abstract}

Keywords: Impact test, High strain rate, P-SHPB, Steel, Damage mode, Aluminum

\section{Introduction}

Understanding the characteristics of failure behavior of steel and aluminum under impact load is of interest in many civil and military applications.Extensive investigations of dynamic behavior of metallicmaterials, such as steel and aluminum materials, in the past two decades have focused on understanding their mechanical properties such as shearing, fatigue, elastic, transverse and tensile properties relative to other materials.Aluminum is considered as a ductile light metal with FCC crystal structure whose behavior under high strain rate load is important for aerospace industries and ferriticsteel with BCC crystal structure is the most applicable metal in the industry. Subhash (2000) compared the static and dynamic indentation and observed that static results may not be appropriate to use as dynamic material properties such as hardness for high velocity conditions. Wosu et al. (Wosu et al., 2006; Ojo et al, 2007) used a modified SHPB bar for studying penetration and fracture mechanics of a variety of materials at high strain rate. Their method showed energy absorbed as an important measure of levels of failure. However, the penetrating Hopkinson bar underestimates the stress-strain curve and absolute mechanical material properties of the test specimen. This is mainly due to the attenuation of the transmitted wave and the inadequacy of the governing equations to account for the corresponding energy losses due to non-linearity in the system. A great deal of research work (Yang, 1988; Nagashima S., 1984; Jiao et al., 2006) has been carried out for better understanding of the mechanical properties of steel. Yu and Topper (Yu \& Topper, 1985) studied the effect of compressive load for the tempered and quenched steel's mechanical 
behavior. They found that both compressive and intermittent compressive loads decrease the threshold for crack growth. Lee et al. (2003) studied the high strain rate behavior of aluminum foam material and 304 stainless steel using dynamic loading and quasi-static loading to investigate different failure mechanisms. It was observed that the deformation caused by quasi-static loading was more concentrated than that of dynamic loading. Jia et al. (2004) and Lee et al. (2003) have investigated the stress-strain relationship for aluminum at high strain rate. The effect of specimen dimensions on the type of dynamic failure was ignored in their results.

In this paper, failure behaviors are compared for steel and aluminum under high strain rate compressive penetration/perforation usingperforating split Hopkinson pressure bar (P-SHPB). Different energy levels are applied on disk shape specimens with two different thicknesses at strain rates in the range between 950 and 5700 $\mathrm{s}^{-1}$. Different damage modes are defined to characterize the deformation of the specimen based on input (impact) energy, peak energy absorbed, strain rate, and stress-strain behavior.

\section{Experimental}

The impact-end of the striker is spherically rounded with a $50.8 \mathrm{~mm}$ radius for a repeatable point of contact with the incident bar on a plane axially normal to the longitudinal direction of the wave propagation. The geometrical shape of the striker and the impact velocity control the shape of the waveform. The stress wave amplitude varies with impact velocity, while the stress profile changes with striker geometry. For interested readers, the authors' previous publications(Allazadeh \&Wosu, 2011, pp: 311-325; Allazadeh \&Wosu, 2011, STRAIN) give detailed information about the P-SHPB setup used in this experiment and summarized in Figure 1.Specimens are made of ferriticstainless steel cast 18-8, and aluminum cast 195-76. Specimens were circular discs of diameter of $52 \mathrm{~mm}$ and thickness of $2.54 \mathrm{~mm}$ and $5.08 \mathrm{~mm}$. The strain wave incident, reflected and transmitted pulses provide information for complete characterization of the damage process. The integration of the strain wave gives the energy absorbed-time history, force-displacement, stress-strain relationship and other relevant data to characterize the specimen damage.

The damage modes are categorized as indentation (Ind), penetration (Pen), perforation (Perf), punch-through (PT) and plugging by visual observation of the damage on the tested specimens. Indentation mode is when the penetrator makes visible damage on the contact surface of the specimen with no visible bulge on the other side. If the contact surface shows a visible damage and the other side has a visible bulge, the damage mode is partial penetration. Perforation damage on the specimen allows light through the opening caused by the impact or occurs when the penetrator-head just exits the rear surface of the specimen. Punch through is defined as when the penetrator-head passes through the specimen and creates a permanent hole. A penetration which causes a mass loss from the specimens by the perforation is known as plugging.

In the perforating SHPB system used in this work, compressed air launches the striker bar against the incident bar at a specific energy level and forms a longitudinal wave that travels along the incident bar. A fraction of this wave is reflected at the interface between the specimen and the incident bar due to an impedance mismatch at the interface, and the rest traverse the specimen and continues to propagate to the transmitter bar.The amplitude of the reflected wave depends on the surface damage or roughness on the specimen, and suggests mechanical information about materials interaction at the surface. Boundary conditions determine the characteristics of the captured wave. In the case of neither free nor fixed boundary conditions, a portion of the stress wavesare reflected from the end of the transmitted bar in direction opposite to initial applied stress. The striker velocity just before impacting the incident bar was measured as a function of impact pressure using two infrared photo gate detectors which detect the motion of two sensors glued on the bars. One sensor was placed on the incident bar and the second one was attached to the transmitted bar. Ojo (2003) showed for the P-SHPB used in this research work,nonlinear curves of perforation velocity $\left(v_{p}\right)$ and striker impact velocity $\left(v_{i}\right)$ versus compressor impact pressure (p) in Pascal, $\mathrm{Pa}$ are given as:

$$
\begin{aligned}
& v_{p}=9 \times 10^{-5} p^{0.7072} \\
& v_{i}=0.0014 p^{0.7007}
\end{aligned}
$$

The corresponding perforation $\left(E_{p}\right)$ and impact energies $\left(E_{i}\right)$ are given by,

$$
E_{p}=\frac{1}{2} m_{p b} v_{p}^{2} \quad ; \quad E_{i}=\frac{1}{2} m_{s b} v_{i}^{2}
$$


Wherethe mass of the penetrating incident bar, $m_{p b}$, is $14.6 \mathrm{~kg}$ and the mass of the striker bar, $m_{s b}$, is $2.47 \mathrm{~kg}$. A protruding hemispherical nosed penetrator ismounted at the end of the incident bar is used.The specimen is placed in a penetrator holder which is mounted at the end of the incident bar. The setup is made such as to allow energy transfer from the incident bar through the specimen to the transmitter bar only via longitudinal waves. Precautions were taken to avoid dynamic movement of the bars and specimen with respect to each other and minimizing the friction effect and perturbation of the waves (more detail in ref. 18 and 19).

Table 1 is the list of the acceptable data captured by the oscilloscope and the strain gages. The oscilloscope's waves are analyzed using Lotus Notes and Excel to get information about the strain and stress at each component of the bar and at specimen using shunt calibration.

\section{Analytical}

Several assumptions for SHPB have been listed in the ASME handbook (Sarafa et al., 2007) articles in which the important ones to develop an analytical computation in this paper are (Wosu et al., 2006; Ojo et al, 2007):

(1). Minor local heat generated during the penetration does not change the material properties of the specimen. The specimensare elastic and wave propagation within the bar follows elementary wave theory.

(2). Considering one dimensional stress state over the slender cross sectional bar for ratio $\mathrm{d} / \mathrm{L}<1 / 50$, where $d$ and $L$ are diameter and length of the bar, respectively.

(3). Shape of the wave is non-dispersive and it remains unchanged during propagation along the bar. That is, planner wave will remain planar and parallel to the cross section during propagation from one section to another.

(4). The state of the stress is in equilibrium along the entire bar at any instant of the dynamic impact by having a long bar and a thin specimen.

(5). Transverse strain, lateral inertia, body forces, parasite waves are all negligible.

(6). Effect of fixture and penetrator's head on the stress waves' configuration in the bars is small enough to be neglected for aluminum specimens in the setup used for these P-SHPB experiments.

For the P-SHPB, it is further assumed that sample strain is much greater than the total strain of the bar and the penetrator-holder setup. These assumptions were carefully investigated for the present setup and found to be satisfied (Hanpu Yang, 1988) or can account for conditions shown in the Figure 2.

With a specimen of the cross sectional area $A_{s}$ placed in a specimen fixture and sandwiched between the incident (input) and transmitter (output) bars of the cross section area $A_{b}$, equilibrium at each interface (input bar/penetrator, penetrator-head/specimen, specimen/fixture, and fixture/output bar) encountered is satisfied by the continuities of forces and velocities at the interface. Dynamic loading of the specimen is provided by the longitudinal impact load, $F_{o}$, of the striker bar resulting in a uniaxial stress pulse generated at the incident bar as shown next;

$$
\sigma(t)=\frac{F_{o}}{A_{b}}=\rho c_{o} v(t)
$$

Where $c_{o}$ is the velocity of the wave pulse in the bar, $v(t)$ is the particle velocity, and $\rho$ is the density of the striker bar material. The particles (atoms at atomistic level or grains at microstructure level) in the incident bar will propagate to the right at a relative velocity of $v_{i}$ in the longitudinal direction of the wave pulse. The amplitude of the incident wave pulse depends on the impact velocity (a function of the applied air pressure) and material properties of the striker. Accurate measurements of the wave pulse and particle velocity in dynamic impact studies are important since the wave train is really the propagation of the disturbance or vibration of the particles.

Neglecting the specimen deflection in this case, equilibrium at the interfaces between the incident (input) and transmitted (output) bars requires that $\sum F=0$ for each interface. Therefore, the absorbed energy can be calculated by the strain measurements on the input and output bars alone, and the geometry of the bars and specimen used in the tests (Sarafa H., et al., 2007; Ramesh, K.T., 1991). The continuity condition of velocity and force equilibrium conditions at the specimen-bar interface gives the specimen particle velocity $\left(v_{s}\right)$ as

$$
v_{s}=\frac{C_{o}}{E_{o}}\left(\sigma_{i}-\sigma_{r}\right)
$$


Subscriptiand $r$ indicate incident and reflected waves, respectively. $C_{0}$ is the velocity of the wave in the Hopkinson bar and $E_{o}$ is the Young's modulus of the Hopkinson bar material. The net bar or specimen relative deformation, $\delta_{n}(t)$, within an effective length of specimen in the path of the waves $\left(L_{e}\right)$ at time $t$ is determined from the wave displacement at positions $X_{1}$ and $X_{2}$ as,

$$
\delta_{n}(t)=U_{1}(t)-U_{2}(t)=\frac{C_{o}}{E_{o}} \int_{0}^{t}\left[\sigma_{i}(t)-\sigma_{r}(t)-\sigma_{t}(t)\right] d t
$$

Subscript $t$ represents the transmitted stress wave. Then, specimen strain, $\varepsilon_{s}(t)$ is calculated as

$$
\varepsilon_{s}=\frac{\delta_{n}(t)}{L_{e}}
$$

In P-SHPB experiment, the specimen is placed inside the fixture, however, the strain of the fixture material is much less than the strain in the specimen. This also supports the assumption 6 . Therefore, $L_{e}$ is approximated as specimen's thickness. Applying Hooke's law stress-strain relationship in equation (6) and combining with equation (7), the specimen strain is,

$$
\varepsilon_{s}(t)=\frac{C_{o}}{L_{e}} \int_{0}^{t}\left[\varepsilon_{i}(t)-\varepsilon_{r}(t)-\varepsilon_{t}(t)\right] d t
$$

In the thinspecimen, the relationship amongstrain waves in the bars at equilibrium is

$$
\varepsilon_{t}(t) \approx \varepsilon_{i}(t)+\varepsilon_{r}(t)
$$

So, the specimen strain can be computed as

$$
\varepsilon_{s}(t)=\frac{-2 C_{o}}{L_{e}} \int_{0}^{t} \varepsilon_{r}(t) d t
$$

andthe average sample stress for a thin specimen is

$$
\bar{\sigma}_{s}(t)=\frac{A_{o}}{A_{s}} \sigma_{t}(t)=\frac{A_{o}}{A_{s}} E_{O} \varepsilon_{t}(t)
$$

For equilibrium at position $\mathrm{x}_{1}$, the continuity force at the interface, $\Sigma \mathrm{F}=0$ in Figure 2 requires that

$$
F_{1}(t)=A_{b}\left(\sigma_{i}(t)+\sigma_{r}(t)\right)=A_{s} \sigma_{t}(t)=F_{s}(t)
$$

the net energy produced by the penetrator and carried by the propagating compressive wave to the specimen is given by

$$
E_{p}(t)=\int_{0}^{t} F_{i}(t) d \delta_{n}
$$

$F_{i}(t)$ is the net compressive loading force given by equation 12 and $\delta_{\mathrm{n}}$ is the net plate deformation given by equation 6 . Intuitively, it can be understood that the energy absorbed by the specimen $\left(E_{A}\right)$ can be given by $\mathrm{E}_{\mathrm{A}}=\mathrm{E}_{\mathrm{i}}-\mathrm{E}_{\mathrm{r}}-\mathrm{E}_{\mathrm{t}}$ after neglecting the energy losses within the penetrator-holder setup. Then, the energy transferred by the propagating compressive wave to the specimen plate $\left(\mathrm{E}_{\mathrm{A}}\right)$ is calculated by substituting equation 6 and 12 into equation 13(Wosu\& Hoy, 2006); 


$$
E_{A}(t)=\frac{A C_{o}}{E_{o}} \int_{0}^{t}\left[\sigma_{i}^{2}(t)-\sigma_{r}^{2}(t)-\sigma_{t}^{2}(t)\right] d t
$$

The value of $E_{A}(t)$ can be decoupled as follows:

$$
E_{A}^{\min }=\Delta E_{a b s} ; \quad E_{A}^{\max }=\Delta E_{a b s}+\Delta E_{s}
$$

The absorbed energy by the specimen reaches to its maximum value if the experimental setup allows the specimen to hold the elastic strain energy of the specimen $\left(\Delta E_{\mathrm{s}}\right)$ in addition to absolute energy absorbed by the specimen $\left(\Delta E_{a b s}\right)$ at time $t$.

\section{Correction for Deviation from Conventional SHPB Formulation}

The theoretical formulation for the P-SHPB or fracturing split Hopkinson pressure bar (F-SHPB) of Figure 1 is based on the classical wave propagation similar for the conventional SHPB (Figure 2) in which the specimen is sandwiched between an incident input and transmitter out-put bar interfaces. The setup for a P-SHPB system in Figure 1 shows that the attachments of the penetrator (indentor) head to the input bar and the specimen fixture to the output bar introduce additional boundaries and interfaces to the system. The fact that the specimen in the specimen fixture is not in direct contact with the transmitter bar further complicates the wave propagation and causes the assumptions on equilibrium and continuity not to be fully achieved in the P-SHBP tests. This is because of deviation from the SHPB stress equilibrium due to attenuations via the interfaces, penetrator and specimen fixtures. Therefore, for penetration or fracture tests, the compliance of the setup must be evaluated against SHPB stress waves at equilibrium state. For most convectional SHPB, specimen reaches about $80-90 \%$ of equilibrium state due to $10-20 \%$ frictional losses in the system. In absolute terms, the difference in peak value of P-SHPB transmitted wave can be 10 times lower than that of SHPB transmitted wavedue to losses to the special penetrator-head and specimen holder.Since the penetrator setup, which includes penetrator head and the sample holder, mainly affects the transmitted waves, the setup compliance is extracted from the equilibrium equation to compensate for these deviations when absolute materials property measurement are required.

Analytical equations for the P-SHPB system can be approximated, and the deviation from equilibrium accounted for, with appropriate corrections of the SHPB formulations. Neglecting attenuation of the reflected wave, the deviation from equilibrium state of the P-SHPB transmitted wave from the conventional SHPB can be accounted for by an experimentally determined correction factor such that:

$$
\varepsilon_{t c}(t)=\left[C_{p t}(t)\right] \varepsilon_{t m}(t)
$$

where, $\varepsilon_{t m}(t)$ and $\varepsilon_{t c}(t)$ are the measured attenuated transmitted strain pulse and the corrected incident strain pulse for the P-SHPB setup, respectively. Hence, $C_{P}(t)$ is an experimentally determined correction factor that normalizes strain measurements in P-SHPB with respect to the strain in the conventional SHPB. We hypothesize that an experimentally determined compliance factor can approximately account for transmitted strain wave deviations between the P-SHPB and the conventional SHPB set up.To determine $C_{P}(t)$, a sample of smooth surface is placed between the bars as in the Figure 2 SHPB setup and the strain wave induced by the striker bar impact energy is measured without the penetrator and sample fixture attached to the incident and transmitter bars, respectively. The measurement is repeated at the same conditions but using the P-SHPB setup (Figure 1) in which the penetrator is attached to the input bar and the sample fixture with the sample inside is attached to the output (transmitter) bar. The striker bar impact energy is chosen below the specimen perforation damage energy threshold. The transmitted wave compliance for P-SHPB set up, $C_{P t}(t)$, is determined as time dependent ratio of the transmitted strain wave $\varepsilon_{t}^{S H P B}(t)$ measured in SHPB setup to the transmitted strain wave $\varepsilon_{t}^{P-S H P B}(t)$ in P-SHPB setup;

$$
C_{p t}(t)=\frac{\varepsilon_{t}^{S H P B}(t)}{\varepsilon_{t}^{P-S H P B}(t)}
$$

Figure 3 shows the time dependent graph of $C_{P t}(t)$ and the plot of $\varepsilon_{t}^{S H P B}(t)$ versus $\varepsilon_{t}^{P-S H P B}(t)$ strain pulses measured from the stain gages ( 1 volt $=833$ micro-strain $)$. The result indicates a significant difference due to attenuation of the P-SHPB wave. $C_{P t}(t)$ is observed to peak after 150 microseconds before decreasing to zero. A 
$4^{\text {th }}$ degree polynomial fit gives a good correlation $(r=0.93$ fit to the experimental data. Fig $3 \mathrm{~b}$ also shows a good correlation $(\mathrm{r}=0.94)$ between the SHPB transmitted strain and the P-SHPB strain waves $((1$ volt $=833$ micro-strain).Comparison of the corrected strain wave with the conventional measurements in Fig 4 shows a close match between the two (the solid line in Fig 4a is for SHPB measurement), agreeing with our hypothesis that experimentally determined set up compliance factor can be used to correct for deviations between the P-SHPB and the conventional set up.Figure $4 \mathrm{~b}$ is an example of compressive stress waves of steel specimen with thickness of $5 \mathrm{~mm}$ for P-SHPB without and with compliance penetrator-sample holder compliance correction factor $\left(C_{p t}(t)\right)$. The correction reduced the deviation to less than $15 \%$ due to other frictional losses not accounted for.

In the case of one dimensional stress waves presented here, the major effect of the penetrator head-sampleholderfixture is to underestimate the absolute mechanical properties such as the elastic modulus and yield strength of the tested materials when Eq. 11 is used to obtain the sample stress. However, the general conclusions on the mechanical behavior of the material from the experiments are not affected by the penetrator-sample holder. The sample strain, sample stress and energy absorbed can be approximated within the deviation range of the experimental values of $C_{p t}(t)$.

\section{Results and Discussion}

The images in Figure 5 show different damage modes in the tested samples of aluminum and steel. The impact energy to initiate a dynamic failure mode is recorded in Table 1 and converted to striker impact energy by Equation 3. Table 2 is the recorded data for the tested specimens accepted for further analysis. These data are the penetration width and height which are the deformation length in transverse and vertical directions to the wave propagation on the impact side of the specimen and also the observed damage modes on the specimen. The minimum striker impact energy to initiate a typical damage mode is the threshold energy to produce that damage mode. Tables 1 and 2 reveal the width of penetration and the depth of penetrationfor increasing impact energy to be inversely correlated for the steel specimens and positively correlated for the aluminum specimens.Specimens Al-24-26 and Al-24-27 have relatively close impact energy on striker bar and the same penetration width and penetration depth but different damage modes. It appears that the threshold of changing plastic deformation level from perforation to plugging damage modes is within this small range of the striker impact energy.

Figure 6 shows a series of incident (compressive) and reflected (tensile) wave stresses. After stress waves pass through the specimen several times because of reflecting of the waves from two ends of the P-SHPB, it is assumed that the sample has reached a state of stress equilibrium, allowing the use of first compression-tension stress wave set for approximate analysis of the damage process by comparing the first incident stress waves with the corresponding transmitting and reflecting waves. The numerical integration is carried out with shifting the time parameter to zero such that all three waves (incident, reflecting and transmitting waves) beginning at the same time and for the same time duration. It was also observed that the amplitude of the reflected and transmitted wave reach a constant value after the first three reflection waves.Figures 7 to 12 show the comparison of different compressive properties for the experimental P-SHPB results.

Figures 7 (a) and 7 (b) are the strain rate -time behavior for aluminum and steel, respectively for same thickness. According to Figure 7, strain rate range is 1800 to $4000 \mathrm{~s}^{-1}$ for impact energy 180 to $318 \mathrm{~J}$ for the aluminum specimens compared to $950-5700 \mathrm{~s}^{-1}$ for impact energy range of 368 to $839 \mathrm{~J}$ for the steel specimens. This shows that for same input energy and thickness, the aluminum sample strain rate is $42 \%$ higher than steel. Three regions can be observed in the plots in Figure7: (i) sharp increase of strain rate at the first short time interval of the test, (ii) constant strain rate region at ultimate level and (iii) gradual decrease in strain rate toward the end of the damage event. The first short time interval (less than $50 \mu \mathrm{s}$ ) is related to elastic stress distribution in the specimens. The nature of the SHPB method prevents the determination of elastic properties of the material within this region because of stress wave reflection, stress non-uniformity and large variation in strain rate during the initial portion of the test (Nwosu, 1996). Flow of stress plastically through a specimen generates a high strain rate in the impact test for the first $300 \mu$ s time interval. The strain rate reaches and remains at its ultimate limit for the wave duration time before the strain hardening of the material and tensile release lowers the strain rate. In Figure 7 (a) and 7 (b), it can be seen that the strain rate of aluminum and steel specimens decrease for thicker specimens despite increasing in striker impact energy (incident compressive stress). Table 2.Strain rate for both steel and aluminum increases withincident compressive stress or impact energy.

Figure8shows strain variation of impact tests for the specimen aluminum (Figure 8a) and steel (Figure 8b) for two different thicknesses.Figure 8 shows that strain in aluminum (whose ductility is higher in comparison to steel) for the same impact energy and thickness is higher than steel's strain. Strain of specimens St-12-16 and St-12-19 shows that the steel specimen's strain increases by $20 \%$ for $14 \%$ increase in impact energy. Doubling 
the impact energy on the specimen from $368 \mathrm{~J}$ on specimen St-12-16 to 839 Jon St-24-31, reduced the strain to half.Increasing the impact energy by $25 \%$ increases the sample strain in specimens Al-12-8 to Al-12-13 by $50 \%$ without change in the damage mode. This is because impact energy above the perforation threshold energy contributes little to sample strain as sample at threshold energy has reached its maximum strain with punch-through or plugging. Materials will remain at the strain with the additional increase in energy without. Therefore, strain may not always be the proper material parameter to predict the damage mode at high strain rate loading condition.

Figure 9shows the changes in the particle velocity as penetration proceeds in aluminum specimen (Figure 9a) and steel specimens (Figure 9b). It is obvious from Figure 9 that plastic deformation of the specimen is proportional to the striker impact velocity since developing higher particle velocity increase the penetration depth. In case of aluminum specimen, increasing the particle velocity from $6 \mathrm{~m} / \mathrm{s}$ to $10 \mathrm{~m} / \mathrm{s}$ introduces a $30 \%$ deeper penetration through the thickness of the specimen. Penetration climbs from $1.8 \mathrm{~mm}$ to $3.5 \mathrm{~mm}$ as the particle velocity increases from $8 \mathrm{~m} / \mathrm{s}$ in St-24-05 to $16 \mathrm{~m} / \mathrm{s}$ in St-24-31. Relating the graphs in Figure 9 with the data in Table 1 proves a direct relationship between the velocity of the particles within the specimen in the impact test and the striker impact energy. Figure 9 also gives a direct relationship between particle's velocity and the deformation of the specimens at high strain rate.

The strain rate in Figure 10 shows a typical plateau region for the strain rate as a function of sample penetration. The width of the plot is a measure of the depth of penetration as penetrator travels through the sample thickness. The result shows higher strain rates and depth of penetration for the high energy events, and implies that the higher damage threshold energy requires the higher strain rate, and therefore, the deeper penetration and deformation of the tested sample. In terms of the damage modes, the strain rate increases from low value at indentation to punch-through, that is, strain rate at penetration is lower than the strain rate of indentation and higher than the strain rate at punch through for the same material.

The stress-strain relationships were plotted in Figure 11with2.5 mm thickness (Figure 11a) and $5 \mathrm{~mm}$ thickness (Figure 11b) for steel and aluminum. The higher the striker impact energy the higher theinduced compressive stress level in the sample.The thinner sample of $2.54 \mathrm{~mm}$ has lower yielding stress, ultimate stress and dynamic modulus than specimens with $5 \mathrm{~mm}$ thickness loaded at the same energy. This means that the thinner material will reach the point of yielding or plastic deformation at lower compressive stress than with thicker sample loaded at the same impact energy.Experimental recorded data of graphs for aluminum specimens in Figure 11 shows that ultimate stresses for the aluminum specimen, with thickness $2.54 \mathrm{~mm}$ (AL-12-13) and $5.08 \mathrm{~mm}$ (Al-24-26), are between $10 \mathrm{MPaand} 23 \mathrm{MPa}$, respectively, compared to their yield stresses of $8 \mathrm{MPa}$ and 18 MPa, respectively. It appears that impact energy above damage threshold does not significantly affect the stress-strain distribution of the material as much as energy below the threshold.This is because once threshold energy for damage is reached additional energy above that level is lost as residual. Table 3 shows that most of the samples were at or higher that the threshold energy for penetration damage.

Figure 12 shows the energy absorption-time history for the specimens tested with thicknesses of 5.08 and 2.54 $\mathrm{mm}$. Four critical energy absorbed levels can be seen in the graphs. These energy levels are yield energy, ultimate (peak) energy, strain-release energy and residual energy. Yield energy is the energy at the end of linearly increasing of energy with respect to time. Ultimate energy is the maximum energy or the peak energy available for the damage process. The strain (release) energy is the first release of absorbed energy by the specimen characterized by force reversal at the rear tensile surface of the specimen and can be determined as the difference betweenultimate energy and residual energy. The residual energy absorbed is the energy at the end of the strain energy released after the $300 \mu \mathrm{s}$ deformation time.The energy absorbed in the aluminum increases from $18.2 \mathrm{~J}$ to $50.5 \mathrm{~J}$ by increasing the thickness of the aluminum sample from $2.54 \mathrm{~mm}$ to $5.08 \mathrm{~mm}$ in the case of the penetration mode, which demonstrates the effect of thickness on the energy absorption of an aluminum sample. Plastic deformation and especially crack formation and propagation produce a large drop in absorbed stress level in the material for the same strain rate. In addition, Figure 12reveals that as ductility of the material increases, the material become less capable to store energy in itself, since the consumed energy is used for the deformation. Therefore, aluminum with higher ductility shows lower values in the graphs in Figure 12(a) in comparison to the graphs of ferritic steel in Figure 12(b). The relation between energy absorbed and damage mode in Figure 12 gives good evidence that the deformation in the specimens is increased as the specimen's ultimate energy absorbed gets larger which results in more catastrophic damage in high strain rate plastic deformation. The results demonstrate that absorbed energy is a good characteristic parameter to predict the damage. Material properties, geometry of specimen and incident stress energy affect the absorbed energy. 
Characteristic results of impact load tests are presented in Table 3 and Table 4. Yield stress and yield strain in Table 3 are higher for thicker specimens for both steel and aluminum specimens. It is evident that absorption of major energy loss between reflected and transmitted waves by the specimens causes one of the defined damage modes. Threshold of impact energy is very critical and the results might change drastically by any small deviation depending on the material properties. Table 4 gives the experimental values of maximum incident, reflecting and transmitting stresses for the tested specimens. It can be seen in Table 4 that the ultimate energy of aluminum specimens with thickness $2.54 \mathrm{~mm}$ is increasing for higher particle velocities which results in deeper penetration of penetrator head into the specimen (see results of AL-12-8 and AL-12-13). The same fact can be concluded for aluminum specimen with thickness of $5.08 \mathrm{~mm}$ from Table 4 (see results of AL-24-26 and AL-24-27). Similar relationship can be found for steel specimens with thickness $2.54 \mathrm{~mm}$ and $5.08 \mathrm{~mm}$ by comparing specimens ST-12-16, ST-12-19 and ST-12 33 with each other and by comparing the results in Table 4 for ST-24-05 with results of ST-24-31.

\section{Conclusions}

The P-SHPB system was used to investigate the dynamic failure of steel, aluminum disk shape specimens. Specimens were fabricated in two different thicknesses for each material to investigate the effect of the geometrical dimension on the behavior of different material in high strain failure. The energy levels and the compressive dynamic failure behavior of the materials were investigated. The experimental results utilized to conclude different relationships among strain, strain rate, stresses at bars, ultimate specimen's stress, specimen's deformation, specimen's thickness and energy absorbed by the specimen out of steel and aluminum material. The following conclusions can be made from the results of the impact load test at high strain rate experiments:

(1) The upper strain rate depends on the specimen's material and thickness.

(2) Strain in depth is higher for steel in comparison to aluminum which might be explained by localization of the strain in case of less ductile material.

(3) The stress strain relationship in the samples doesn't change significantly for the specimen with the same thickness and material, however, the damage on the specimen becomes more catastrophic.

(4) Higher strain is obtained in higher energy events (such as in punch-through damage mode) than in lower energy event (such as indentation), however, for thicker specimens is smaller in case of both aluminum and steel specimens.

Although more impact tests are required to examine the above conclusions, these experiments confirmed some of the results obtained by previous researchers and gave experimental data for researchers and industries interested in mechanical behavior of steel and aluminum at high strain rate events.

\section{References}

Allazadeh M. R., \& Wosu Sylvanus N. (2011). High Strain Rate Compressive Tests on Woven Graphite Epoxy Composites. Chemistry and Materials Science, Applied Composite Materials, Volume 18, Number 4, pp: 311-325, (August 2011). http://dx.doi.org/10.1007/s10443-010-9159-6

Allazadeh M. R., \& Wosu Sylvanus N. (2011). High Strain Rate Compressive Tests on Wood. Strain, An international Journal for Experimental Mechanics, STRAIN- (26 JAN 2011). http://dx.doi.org/10.1111/j.1475-1305.2010.00802

Hanpu, Yang. (1988). Corrosion Study on Dual-Phase Steel 0. 08C-Cu-P-Cr-Ni-Mo. Kang T'ieh/Iron and Steel, v23, n1, Jan, p 44-51.

Jia, D., \& Ramesh, K.T. (2004). Rigorous assessment of the benefits of miniaturization in the Kolsky bar system. Society of experimental mechanics.

Jiao, Chu-Jie, Sun, Wei, \& Gao, Pei-Zheng. (2006). Dynamic mechanical properties of steel-fiber reinforced ultrahigh strength concrete. Gongcheng Lixue/Engineering Mechanics, v23, n8, August, 2006, p 85-89.

Lee, S., Barthelat, F., \& Espinosa, H.D. (2003). Strain rate effects in metallic cellular materials. Proceedings of the 2003 SEN annual conference and exposition on experimental and applied mechanics, June 2-4, charlotte, North Carolina, session 37, paper 188.

Nagashima, S. (1984). Anisotropy in Mechanical Properties And Texture Control In Steel Making Technology. Netherlands Soc for Materials Science, p 369-382.

Nwosu S. N. (1996). Hopkinson bar perforation of Laminated graphite/ epoxy composite. USAFORS report WL-TR-96-3080, ppl-66. 
Ojo O. B., Wosu S. N., Onipede D., \& W. Slaughter. (2006). Effect of Penetrator Size on the Dynamic failure Response of Woven Graphite Epoxy Composites around the critical Perforation Energy. J. ASTM International, Vol. 4, No. 4.

Ojo, O. B. (2003). Effect of penetrator configuration and size on the dynamic behavior of composite material under high strain rate loading.University of Pittsburgh, Department of Mechanical engineering Master thesis.

Ramesh, K.T. (1991). The short-time compressibility of elasto-hydrodynamic lubricants. Journal of Tribology, 113, 361-371. http://dx.doi.org/10.1115/1.2920630

Sarafa H., Ramesha K.T., Lennonb A.M., Merkleb A.C., \& Robert J.C. (2007). Mechanical properties of soft human tissues under dynamic loading. Journal of Biomechanics, 40, 1960-1967. http://dx.doi.org/10.1016/j.jbiomech.2006.09.021

Subhash G. (2000). Dynamic Indentation Testing. ASM Handbook, Mechanical Testing and Evaluation, Volume 8, ASM International, 519-529.

WosuS. N., \& Hoy D. (2006). Digital Imaging and Fractographical Analyses of Perforation-Induced Delamination of Laminated Graphite/Epoxy Composite. Journal of Composite Materials, Vol 40, No. 17, 1577-1602. http://dx.doi.org/10.1177/0021998306060163

Yu, M.T., \& Topper, T.H. (1985). The effects of material strength, stress ratio, and compressive overload on the threshold behavior of SAE1045 steel. Journal of engineering material and technology, Vol. 107. pp 19-25. http://dx.doi.org/10.1115/1.3225765

Table 1. Experimental data recorded during the experiment

\begin{tabular}{cccc}
\hline \hline Specimen ID & Thickness $(\mathrm{mm})$ & $\begin{array}{c}\text { Compressed Air Pressure } \\
\text { for Striker Bar }(\mathrm{kPa})\end{array}$ & $\begin{array}{c}\text { Striker Impact Energy } \\
(\mathrm{J})\end{array}$ \\
\hline AL-12-8 & 2.54 & 414 & 180 \\
AL-12-13 & 2.54 & 517 & 246 \\
AL-24-27 & 5.08 & 600 & 303 \\
AL-24-26 & 5.08 & 621 & 318 \\
ST-12-16 & 2.54 & 690 & 368 \\
ST-12-19 & 2.54 & 827 & 476 \\
ST-12-33 & 2.54 & 896 & 532 \\
ST-24-05 & 5.08 & 483 & 223 \\
ST-24-31 & 5.08 & 1241 & 839 \\
\hline
\end{tabular}


Table 2. Characteristics experimental results of the tested specimen

\begin{tabular}{cccc}
\hline \hline Specimen ID & $\begin{array}{c}\text { Penetrating height } \\
(\mathrm{mm})\end{array}$ & $\begin{array}{c}\text { Width of penetration } \\
(\mathrm{mm})\end{array}$ & Damage Mode \\
\hline AL-12-8 & 3.56 & 4.06 & Penetration \\
AL-12-13 & 5.08 & 5.59 & Penetration \\
AL-24-27 & 7.11 & 7.11 & Perforation \\
AL-24-26 & 6.35 & 6.35 & Plugging \\
ST-12-16 & 7.37 & 8.13 & Indentation. \\
ST-12-19 & 8.13 & 7.87 & Penetration \\
ST-12-33 & 8.64 & 6.35 & Plugging \\
ST-24-05 & too small & too small & Indentation \\
ST-24-31 & 7.37 & 7.11 & Penetration \\
\hline
\end{tabular}

Table 3. Mechanical properties of specimens

\begin{tabular}{ccccccccc}
\hline \hline & Strain & $\begin{array}{c}\text { Yield } \\
\text { strain } \\
(\%)\end{array}$ & $\begin{array}{c}\text { Yield } \\
\text { stress } \\
(\mathrm{MPa})\end{array}$ & $\begin{array}{c}\text { Dynamic } \\
\text { modulus } \\
(\mathrm{GPa})\end{array}$ & $\begin{array}{c}\text { Modulus } \\
\text { of } \\
\text { Elasticity } \\
(\mathrm{MPa})\end{array}$ & $\begin{array}{c}\text { Yield } \\
\text { energy } \\
(\mathrm{J})\end{array}$ & $\begin{array}{c}\text { Relaxing } \\
\text { energy } \\
(\mathrm{J})\end{array}$ & $\begin{array}{c}\text { Energy at } \\
400 \mu \mathrm{\mu s}(\mathrm{J})\end{array}$ \\
\hline AL-12-13 & 3581.12 & 32 & 7.24 & 287.14 & 1.45 & 24.34 & 32.85 & 32.38 \\
AL-12-8 & 2821.91 & 24 & 7.24 & 702.75 & 1.09 & 17.45 & 12.98 & 10.33 \\
AL-24-27 & 3818.95 & 38 & 16.55 & 287.70 & 0.75 & 29.34 & 46.12 & 44.61 \\
ST-12-19 & 4742.82 & 20 & 4.83 & 4929.30 & 1.36 & 26.71 & 30.35 & 31.09 \\
ST-12-16 & 4244.29 & 25 & 5.52 & 200.92 & 1.49 & 24.60 & 25.20 & 26.07 \\
ST-12-33 & 4957.78 & 24 & 5.45 & 432.40 & 1.44 & 36.68 & 36.84 & 36.41 \\
ST-24-31 & 5936.52 & 25 & 17.24 & 528.14 & 0.48 & 57.86 & 67.92 & 62.76 \\
\hline
\end{tabular}

Table 4. Numerical analysis data of the captured waves

\begin{tabular}{cccccccc}
\hline \hline Specimen & $\begin{array}{c}\text { Stress-i } \\
\text { nc. }\end{array}$ & $\begin{array}{c}\text { Stress-r } \\
\text { ef. } \\
\text { ID }\end{array}$ & $\begin{array}{c}\text { Stress-t } \\
\text { ran. }\end{array}$ & $\begin{array}{c}\text { Force } \\
(\mathrm{MPa})\end{array}$ & $\begin{array}{c}\text { Ultimate } \\
\text { energy }(\mathrm{JPa})\end{array}$ & $\begin{array}{c}\text { Penetration } \\
(\mathrm{mPm})\end{array}$ & $\begin{array}{c}\text { Velocity } \\
(\mathrm{m} / \mathrm{s})\end{array}$ \\
\hline AL-12-13 & 231.94 & 20.13 & 31.16 & 116.54 & 37.59 & 2.20 & 10.11 \\
AL-12-8 & 175.40 & 87.43 & 52.68 & 92.40 & 19.49 & 1.40 & 8.05 \\
AL-24-26 & 252.07 & 108.94 & 46.61 & 128.83 & 52.23 & 2.30 & 10.93 \\
AL-24-27 & 248.21 & 89.91 & 47.71 & 130.92 & 50.54 & 2.20 & 10.83 \\
ST-12-19 & 290.96 & 37.78 & 32.54 & 166.23 & 38.03 & 3.00 & 13.66 \\
ST-12-16 & 257.31 & 34.47 & 29.23 & 147.67 & 30.09 & 2.70 & 12.04 \\
ST-12-33 & 309.71 & 48.54 & 45.51 & 177.68 & 45.60 & 3.10 & 14.06 \\
ST-24-31 & 361.01 & 103.15 & 76.95 & 213.97 & 75.07 & 3.30 & 16.49 \\
ST-24-5 & 215.67 & 132.93 & 64.53 & 121.01 & 42.58 & 1.80 & 9.41 \\
\hline
\end{tabular}



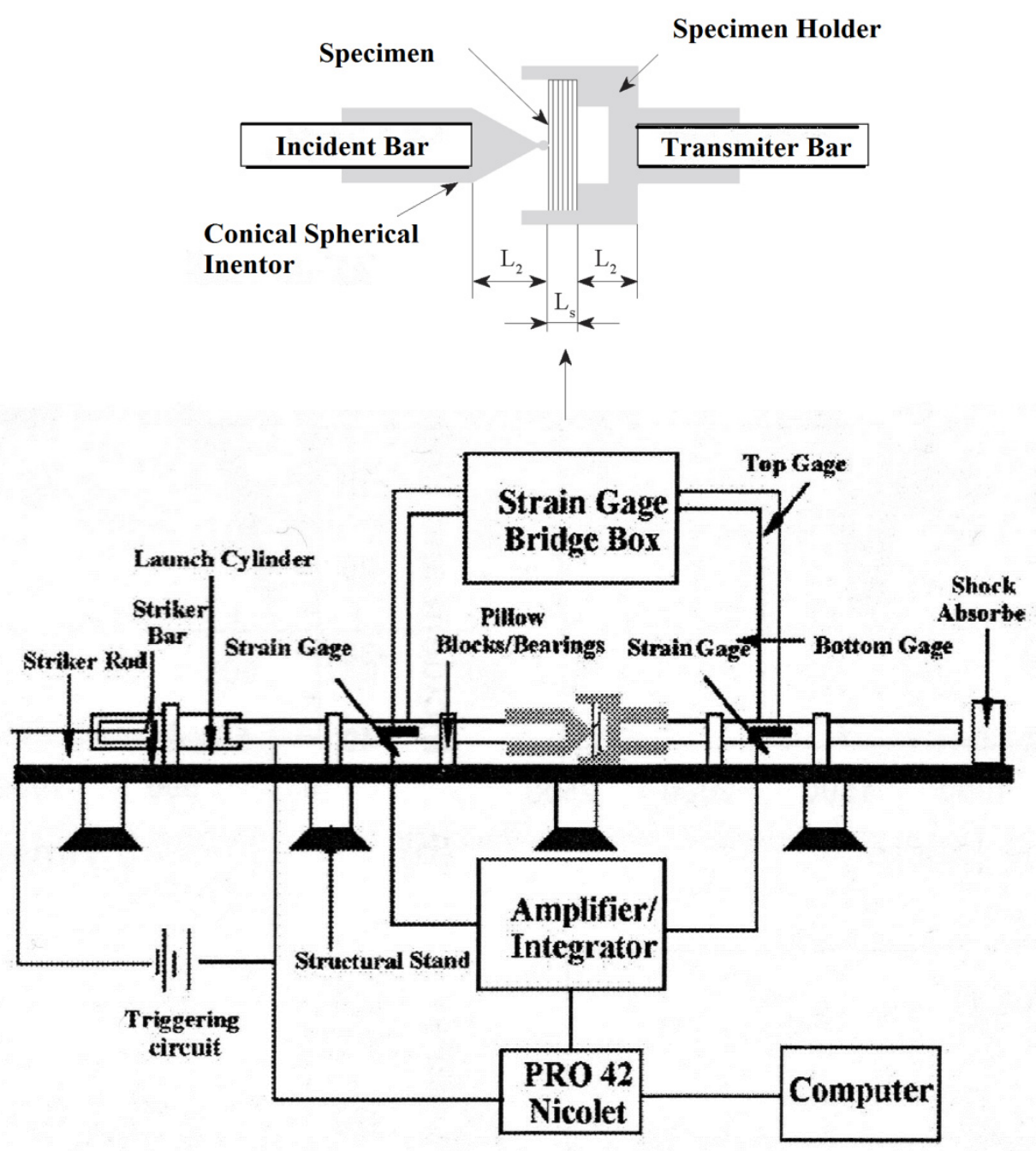

Figure 1. Experimental and data acquisition of the P-SHPB system setup

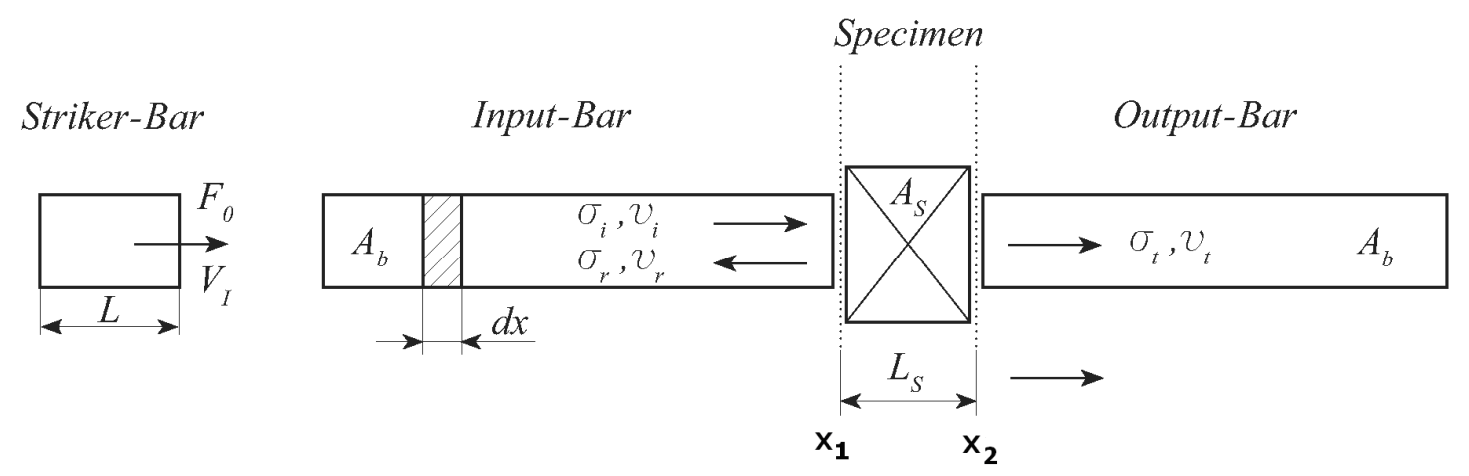

Figure 2. Schematic illustration of wave propagation for the conventional SHPB 


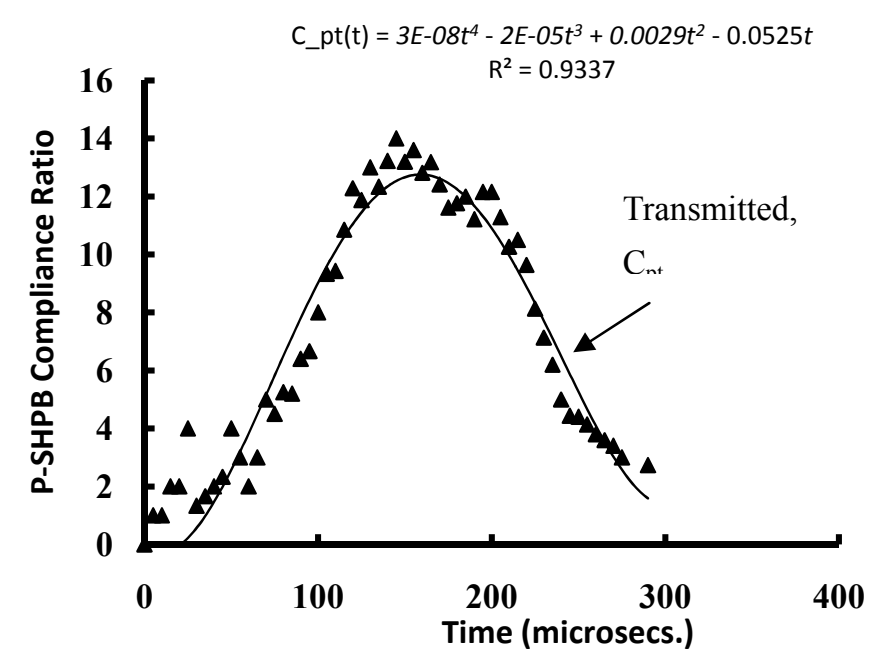

(a)

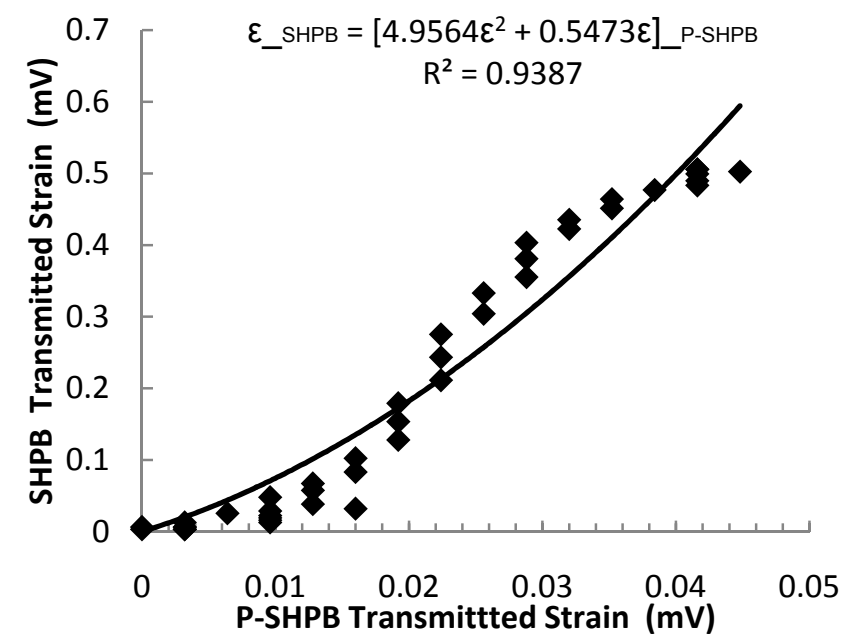

(b)

Figure 3. (a) Time variation of P-SHPB Compliance ratio and (b) correlation of SHPB and P-SHPB transmitted strain wave for the first 200 microseconds 

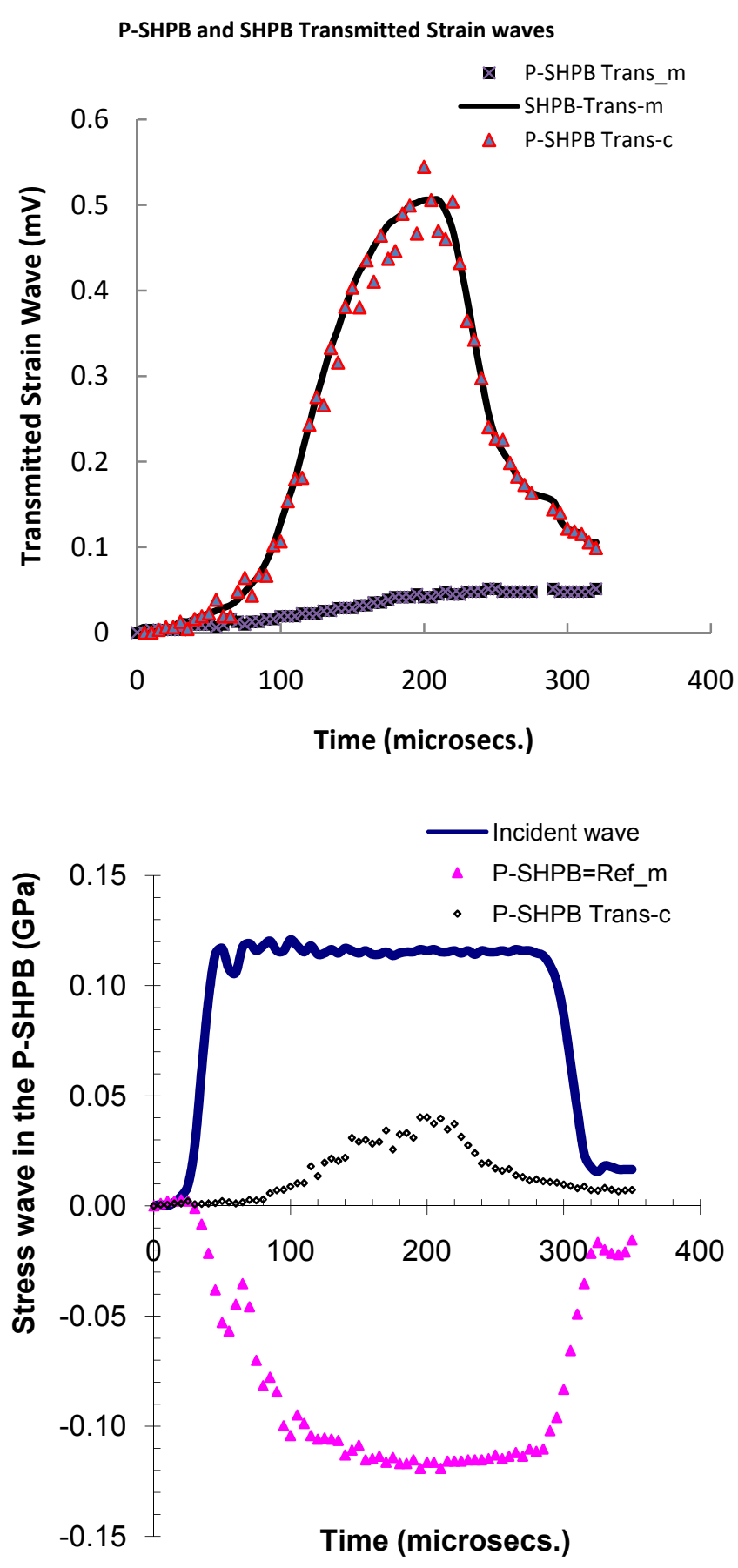

(a)

(b)

Figure 4. (a) Comparison of measured (m) and corrected (c) transmitted waves for P-SHPB and conventional SHPB (solid line) and (b) Corrected P-SHPB transmitted stress wave compared to incident and reflected stress waves for ST-24-31 ( $1 \mathrm{v}=833$ microstrain $)$ 


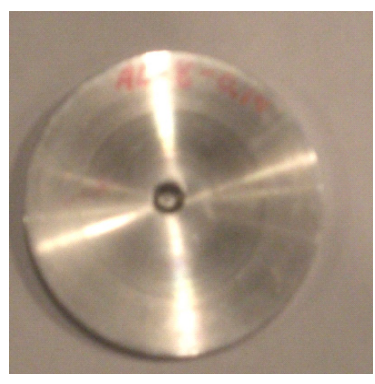

Aluminum: Penetration

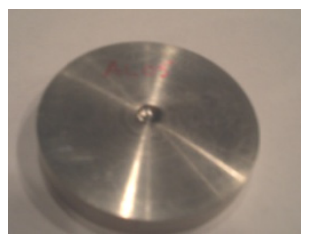

Steel: Indentation

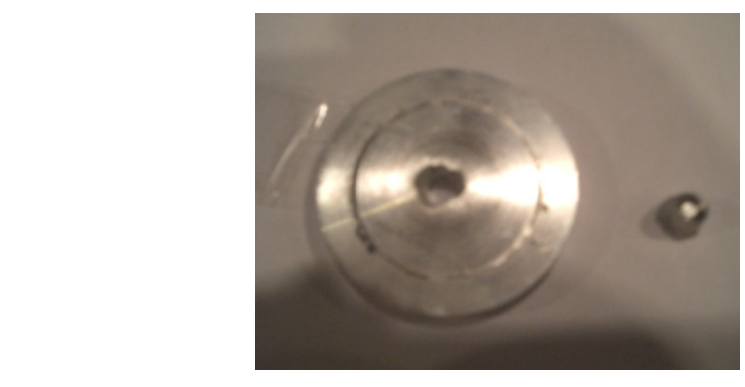

Aluminum: Plugging

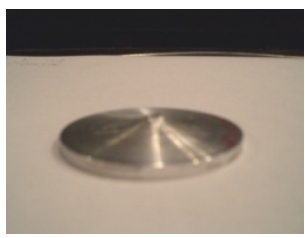

Steel: Penetration

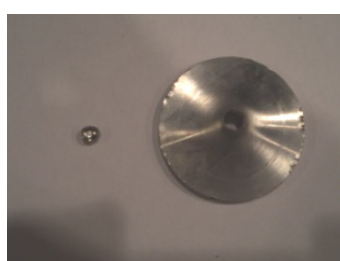

Steel: Plugging

Figure 5. Images of different damage modes in the tested aluminum and steel specimens

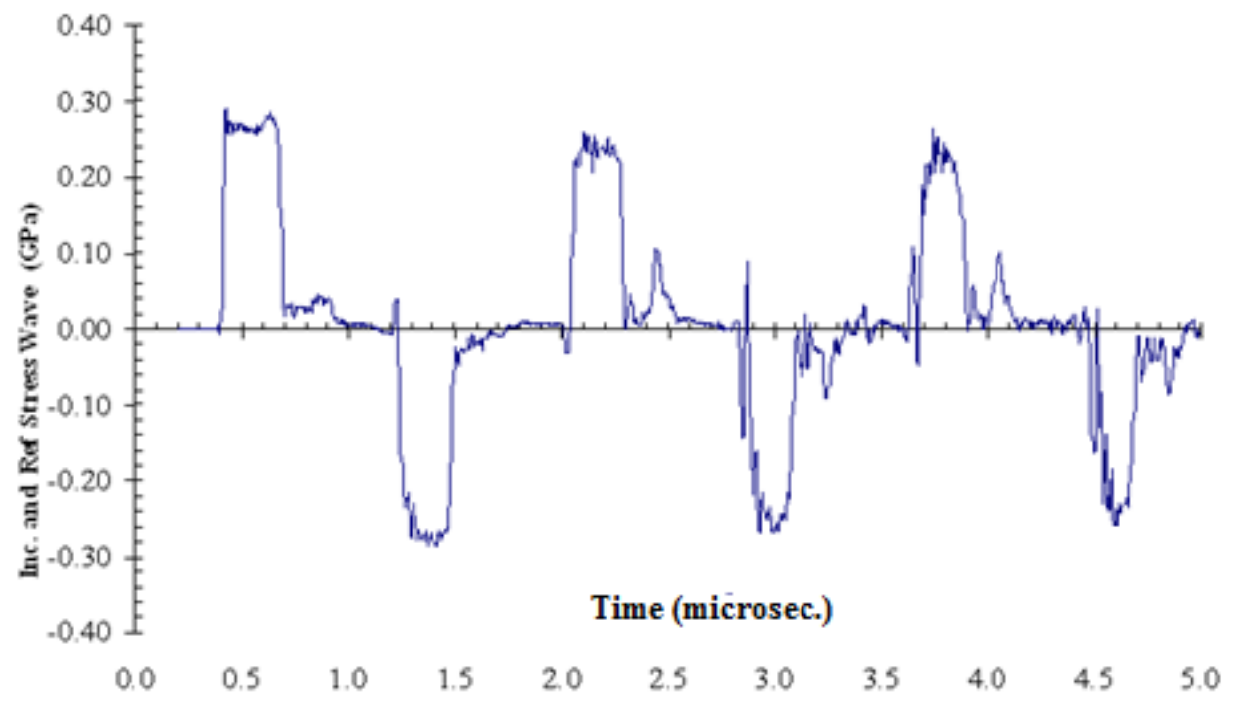

Figure 6. Incident and reflected stress waves on the bar captured by the oscilloscope of ST-12-19 


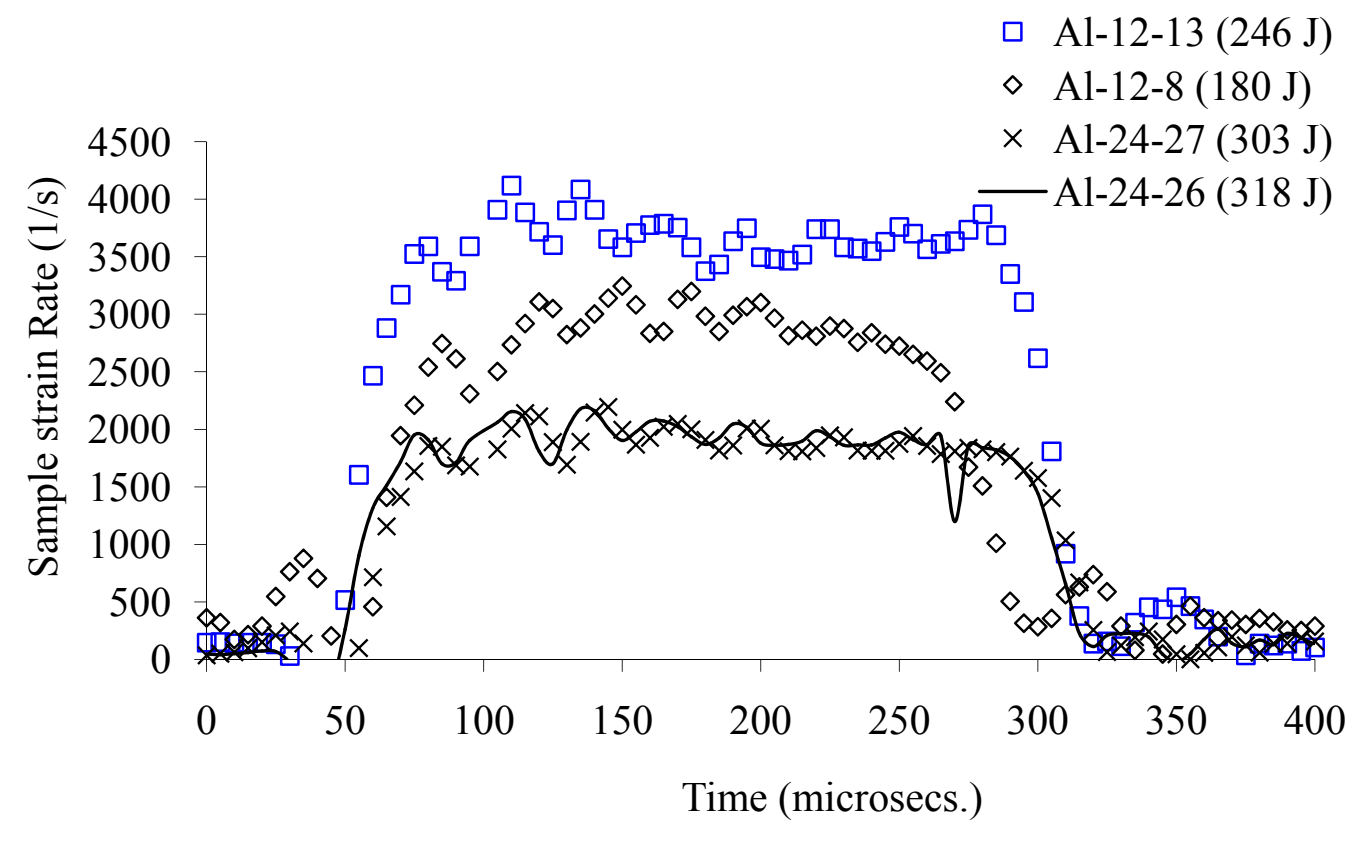

(a)

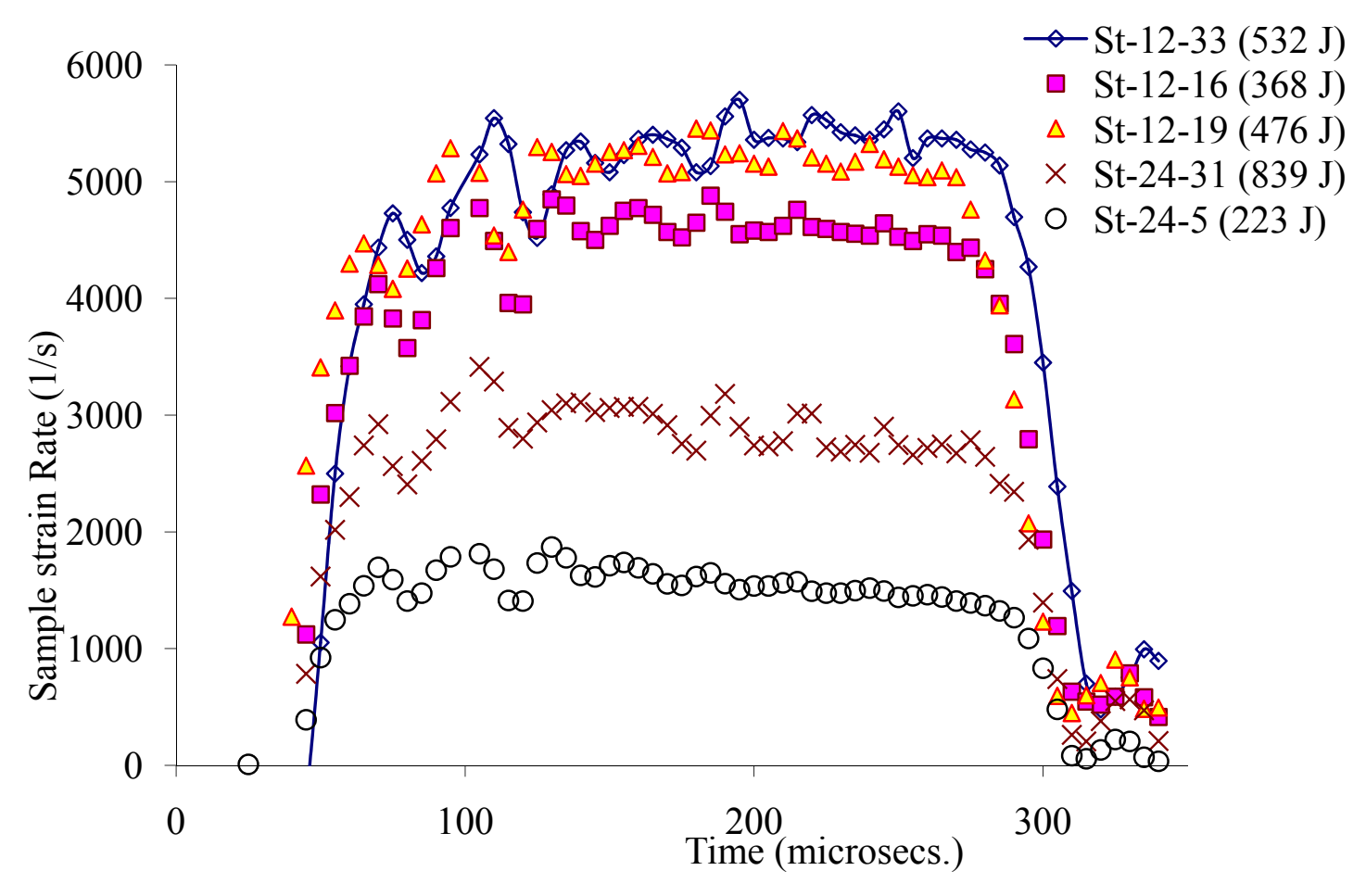

(b)

Figure 7. Sample strain rate variation of the specimens made of (a) aluminum (b) steel 


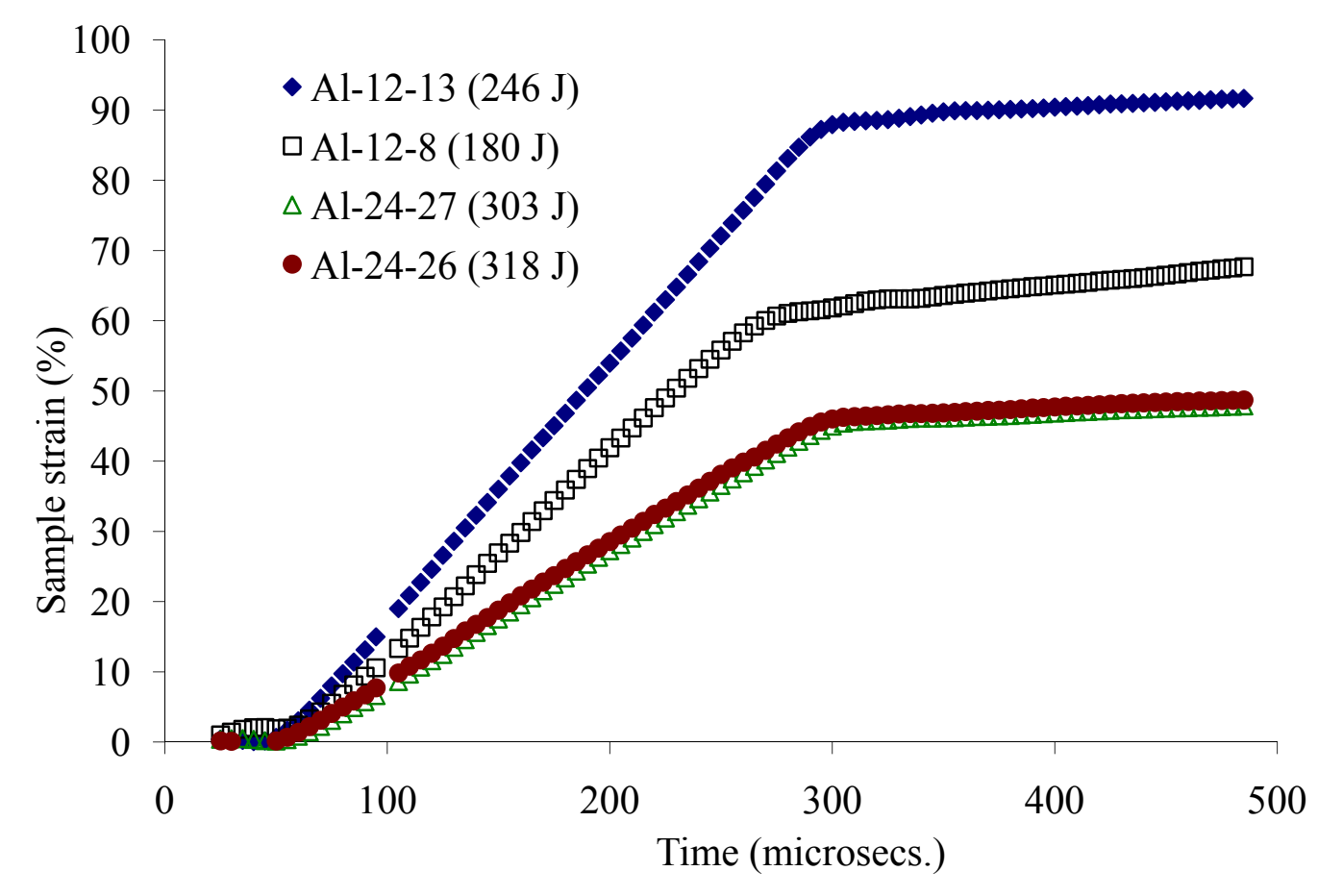

(a)

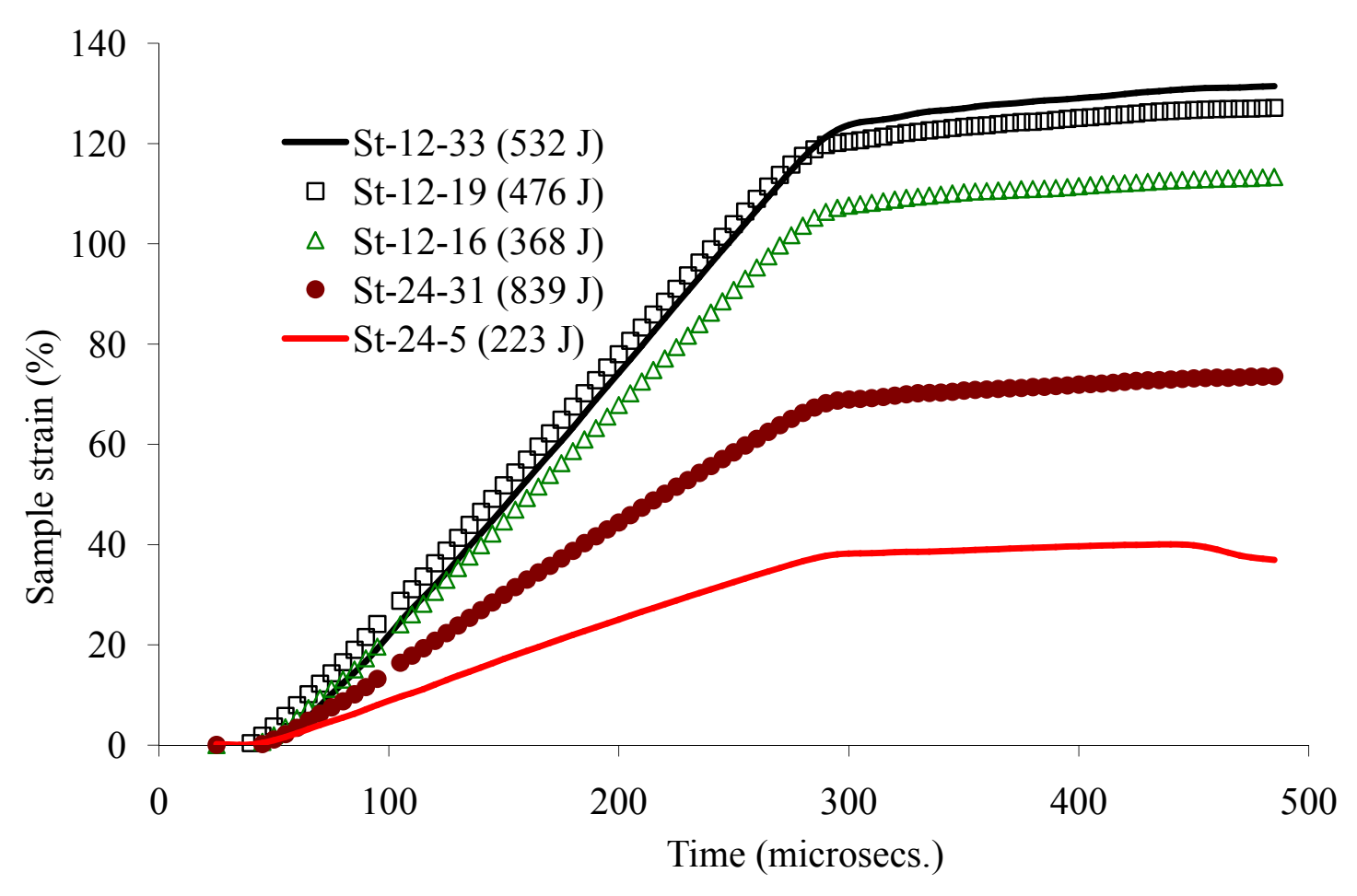

(b)

Figure 8. Sample strain variations of impact tests for the specimens' particles made of (a) aluminum (b) steel 


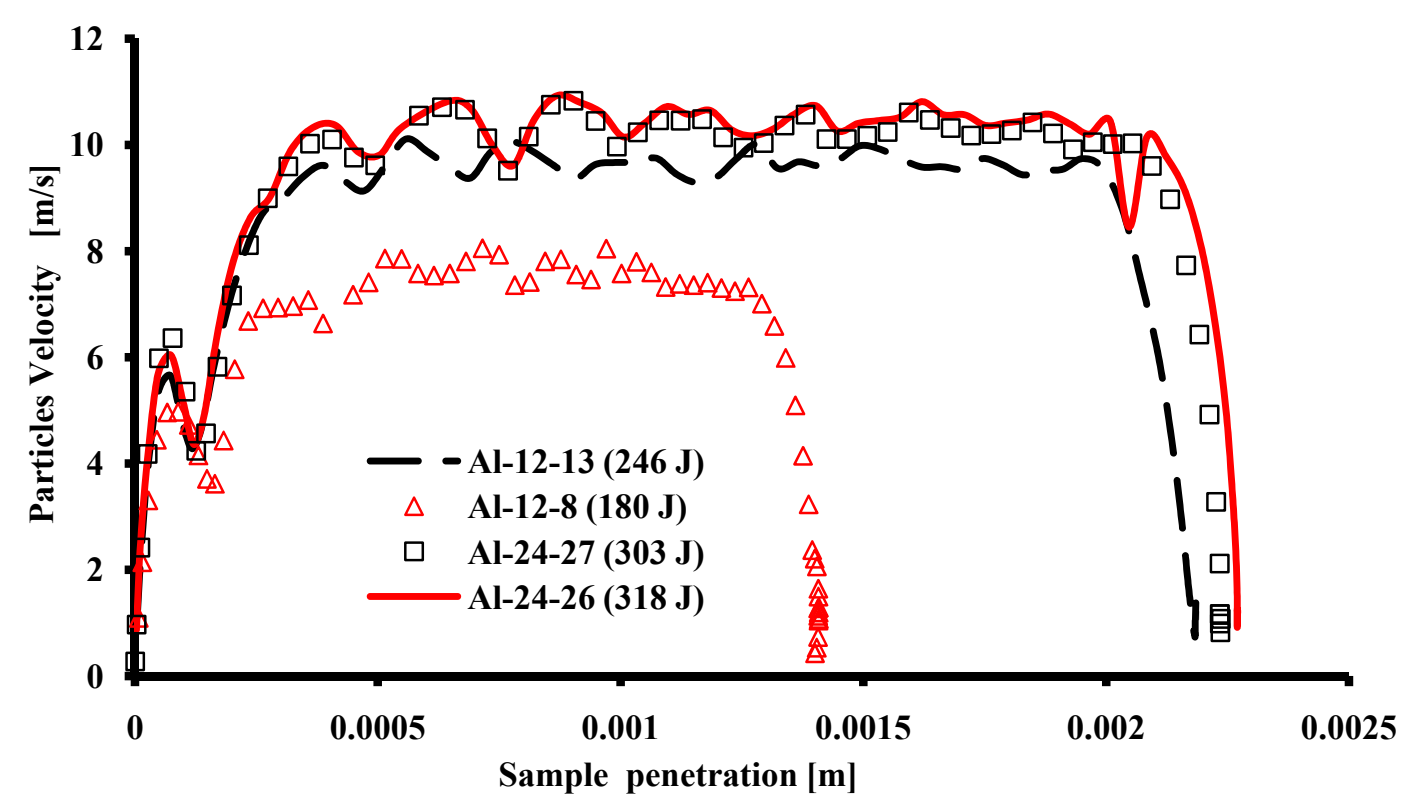

(a)

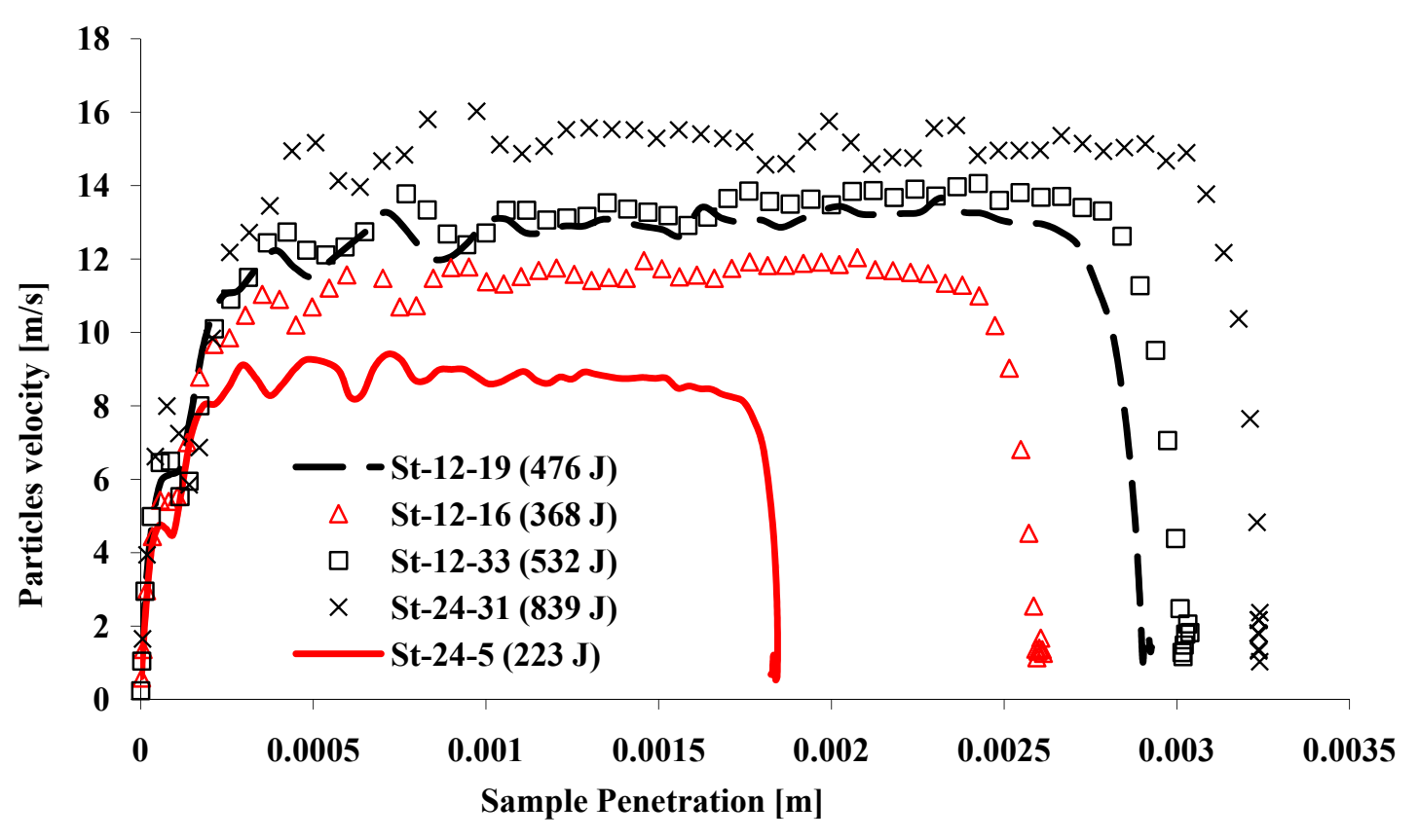

(b)

Figure 9. Particle velocity versus depth of penetration in specimens made of (a) aluminum (b) steel 


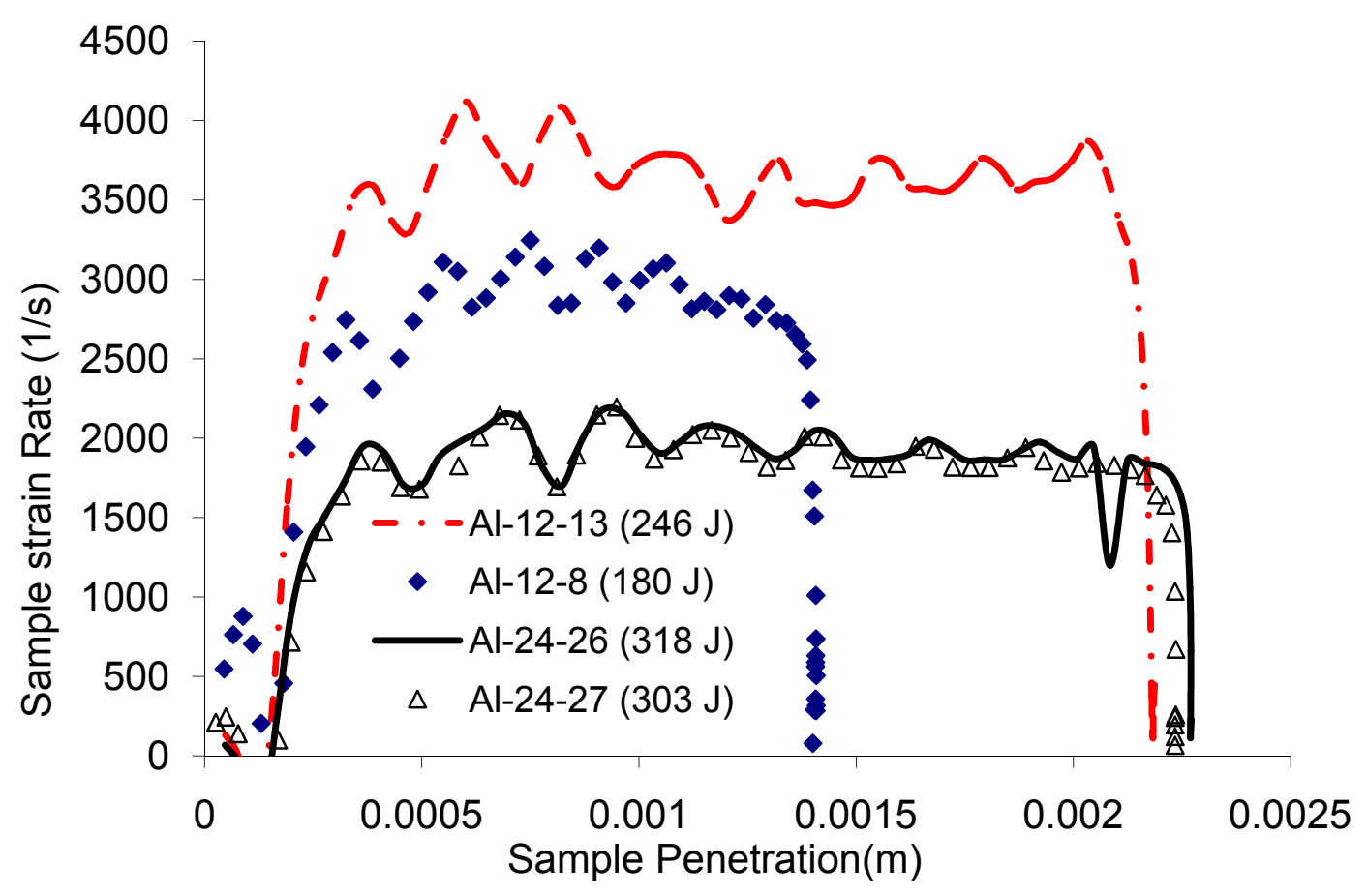

(a)

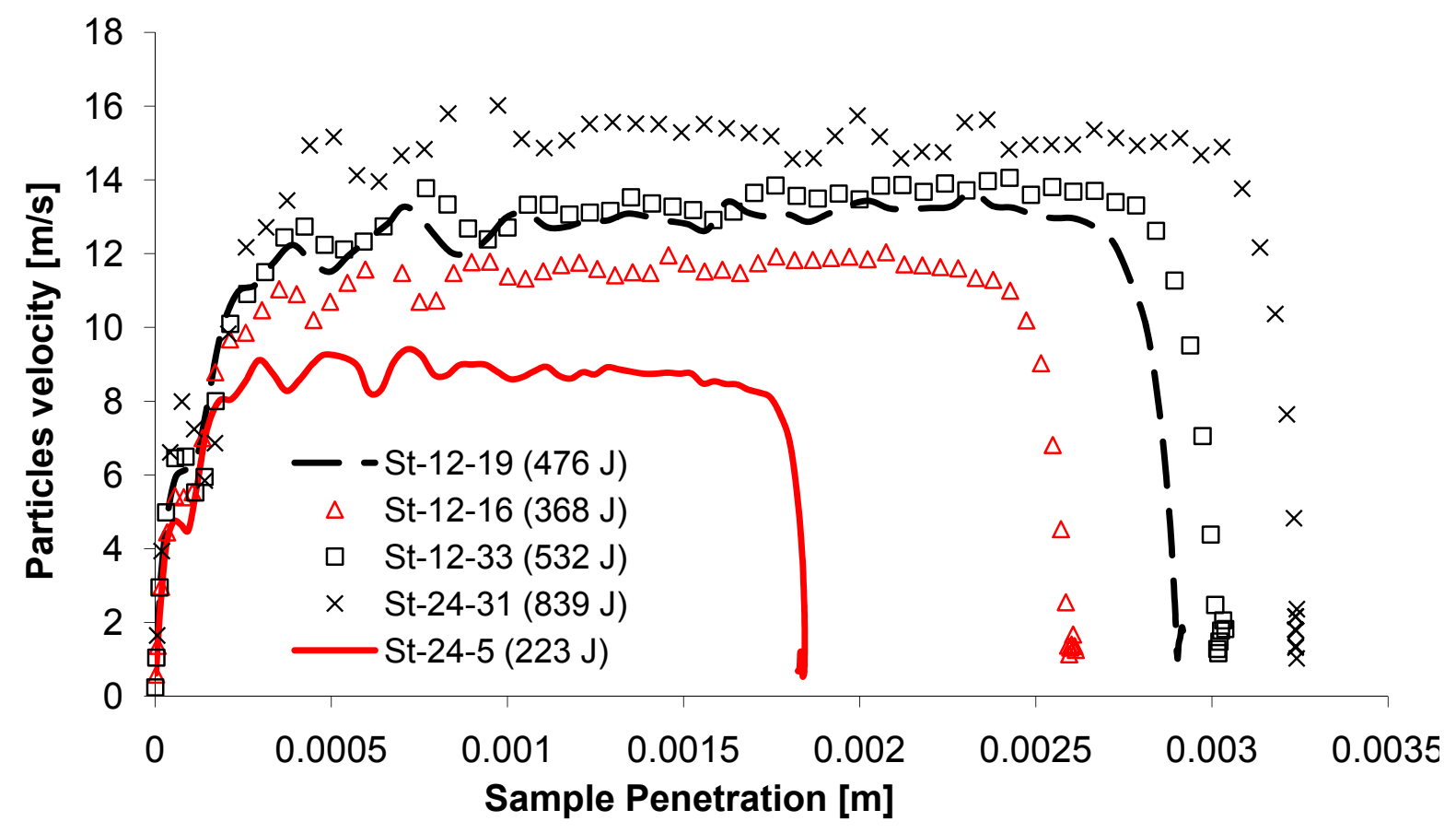

(b)

Figure 10. Sample strain rate variations versus sample penetration through thickness of specimens made of (a) aluminum (b) steel 


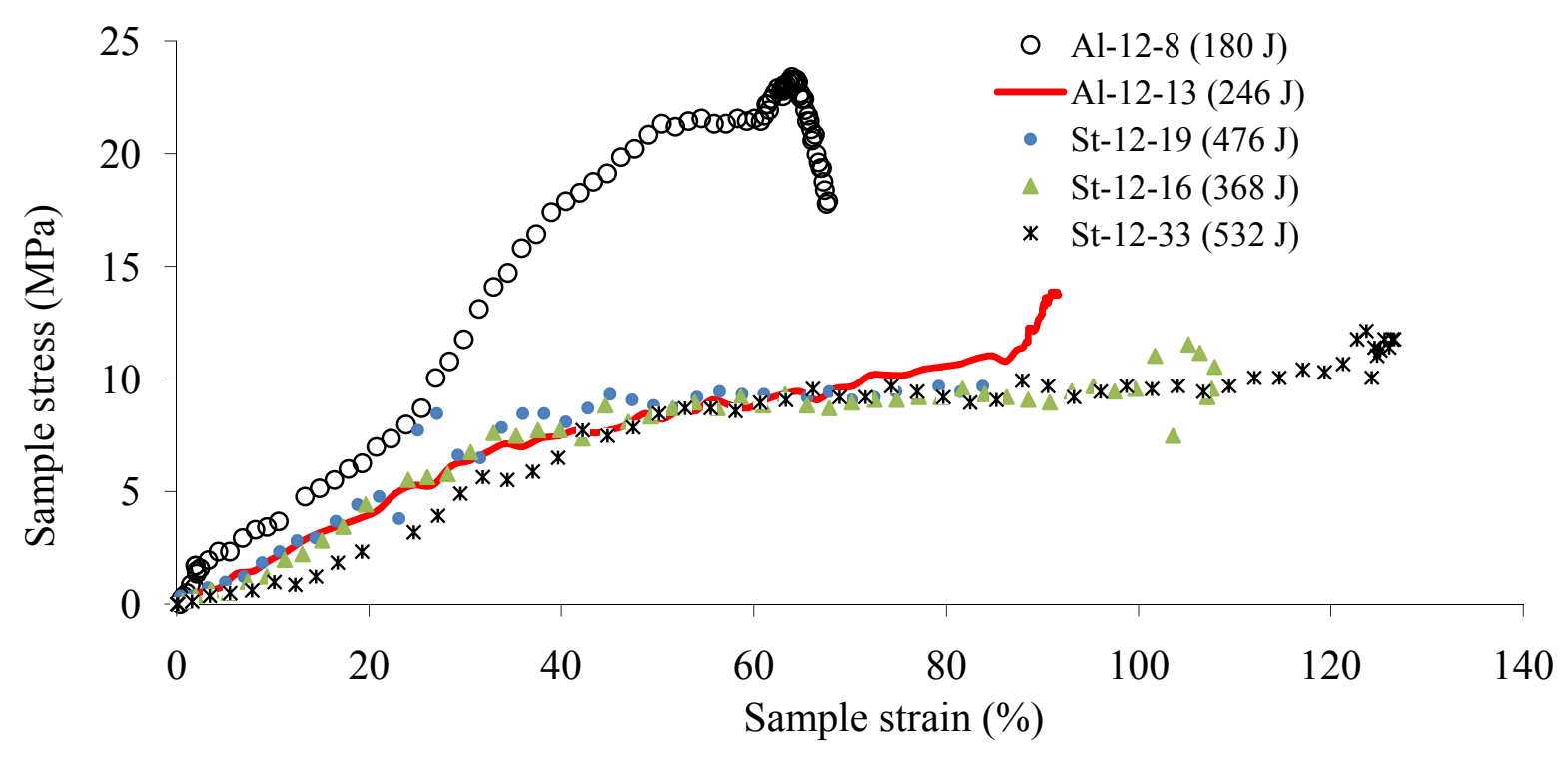

(a)

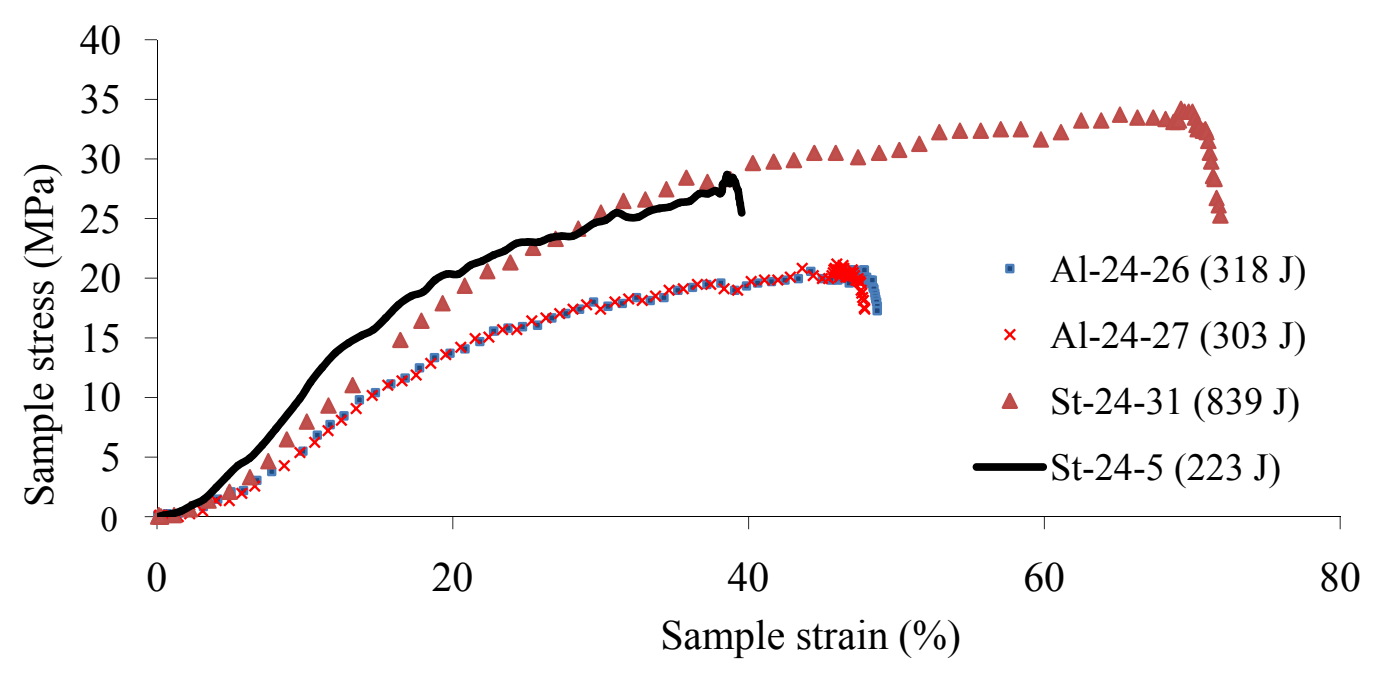

(b)

Figure 11. Specimen's stress-strain relationship at high strain rate experiments for the specimens made of (a) $2.5 \mathrm{~mm}$ (b) $5 \mathrm{~mm}$ 


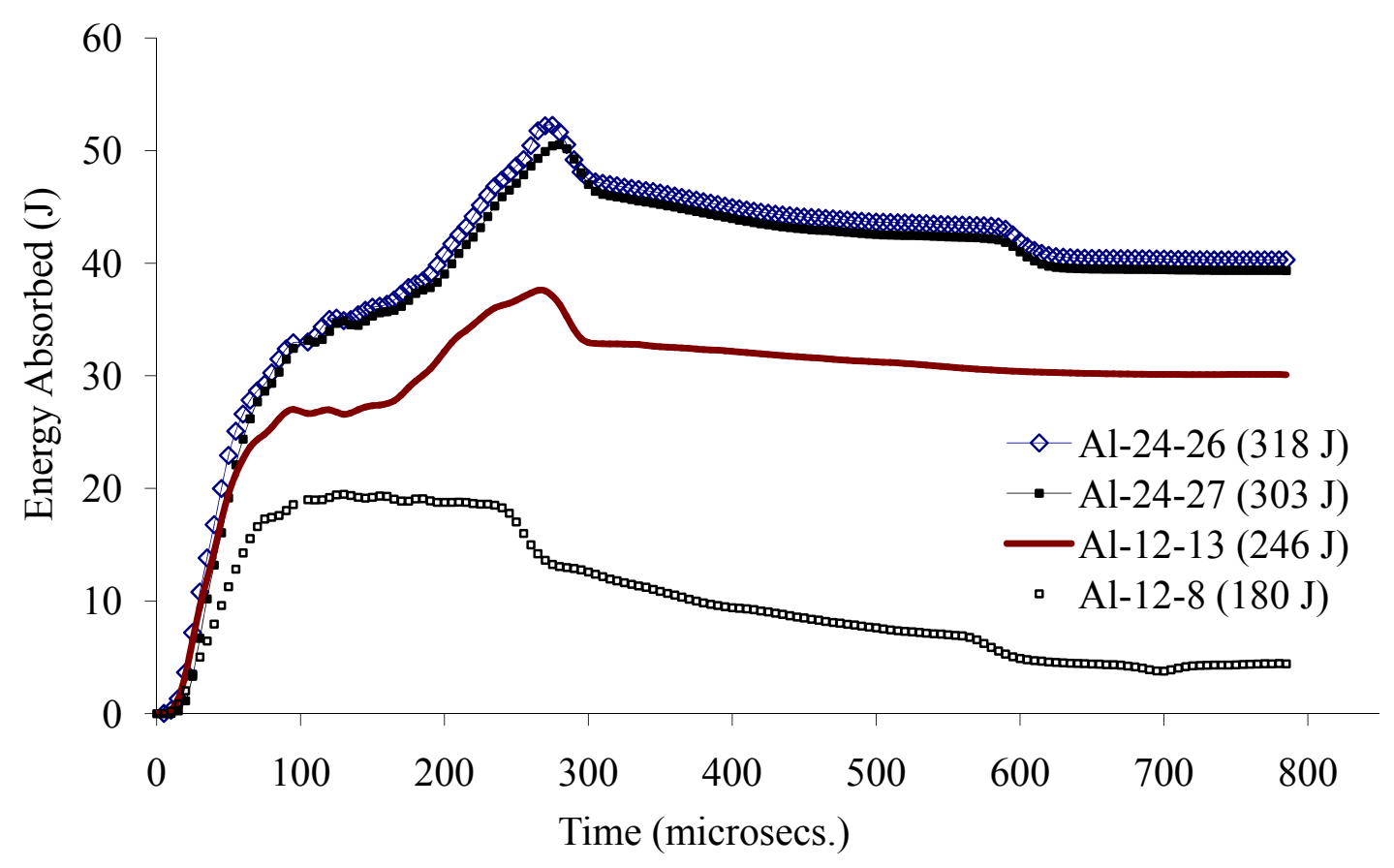

(a)

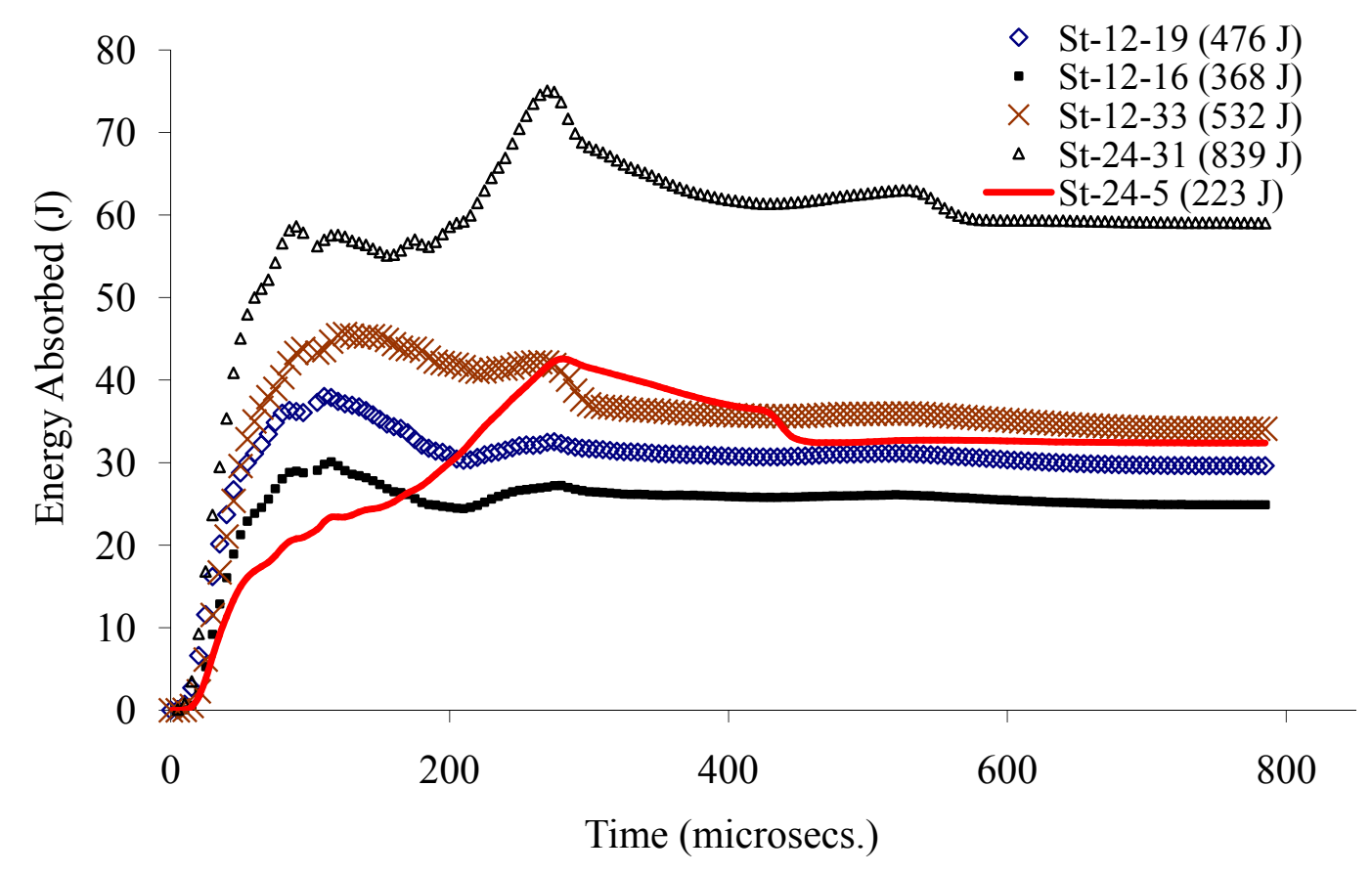

(b)

Figure 12. Energy absorbed within the specimen during impact tests for the specimens' particles made of

(a) aluminum (b) steel 